\title{
Single-nucleotide polymorphisms in the promoter of the CDK5 gene and lung cancer risk in a Korean population
}

\author{
Hyo Seon Choi ${ }^{1}$, Youngin Lee ${ }^{2}$, Kyong Hwa Park ${ }^{3}$, Jae Sook Sung ${ }^{1,4}$, Jong-Eun Lee ${ }^{5}$, Eun-Soon Shin ${ }^{5}$, \\ Jeong-Seon $\mathrm{Ryu}^{6}$ and Yeul Hong Kim ${ }^{1,3,4}$
}

Cyclin-dependent kinase 5 (CDK5), a proline-directed serine/threonine kinase, which was originally known for its regulatory role in neuronal activities, has recently been suggested to play a role in extraneuronal activities. For example, a recent study detected overexpression of the CDK5 gene in non-small-cell lung cancer. Therefore, in order to explore the association of the $C D K 5$ gene with lung cancer risk in a Korean population, the genotypes of the CDK5 promoter region were determined in 407 lung cancer patients and 402 normal participants. The result showed that the $-904 \mathrm{G}>\mathrm{A}$ genotype affected susceptibility to lung cancer risk (odd ratios $(\mathrm{OR})=1.53,95 \%$ confidence interval $(\mathrm{CI})=1.02-2.32$ ). Furthermore, subsequent haplotype analysis of three single-nucleotide polymorphism (SNP) regions suggested that the A-G-C haplotype was associated with a higher overall risk of lung cancer $(O R=1.59,95 \% \mathrm{Cl}=1.16-2.18)$. These results suggest that $C D K 5$ promoter polymorphisms contribute to the genetic susceptibility to lung cancer in the Korean population.

Journal of Human Genetics (2009) 54, 298-303; doi:10.1038/jhg.2009.29; published online 3 April 2009

Keywords: cyclin-dependent kinase 5 (CDK5); lung cancer; single-nucleotide polymorphism

\section{INTRODUCTION}

Cyclin-dependent kinase 5 (CDK5), located in 7q36 chromosome, is a proline-directed serine/threonine kinase that was originally identified as a member of the CDK family, on the basis of sequence homology. ${ }^{1,2}$ It is activated by $\mathrm{p} 35 \mathrm{Nck} 5 \mathrm{a}$, which is autophosphorylated into a complex with CDK5. ${ }^{3}$ Although it is classified as a CDK, CDK5 does not regulate cell cycle. ${ }^{4} \mathrm{CDK} 5$ is recognized as an essential molecule in the brain, where it regulates several neuronal activities, including cytoskeletal remodeling and synaptic transmission. There is presently a substantial amount of data to indicate that CDK5 plays important roles in extraneuronal cells during the process of myogenesis, lens differentiation, spermatogenesis, insulin secretion, apoptosis of ovarian cells and hematopoietic cell differentiation. ${ }^{3,5-11}$

Furthermore, CDK5 has been suggested to play roles in the regulation of motility of prostate cancer cells, ${ }^{12}$ control of glioblastoma cell invasion, ${ }^{13}$ modulation of proliferation of medullary thyroid carcinoma cells ${ }^{14}$ and apoptotic control of leukemia cells. ${ }^{15}$ These potential roles of CDK5 activity in the carcinogenesis of each cell type seem to involve distinct target substrates. ${ }^{16}$

Frequent amplification and overexpression of the CDK5 gene along with multiple epidermal growth factor receptor (EGFR)-family-signal- ing pathway components, including SHC1, AKT1 and MYC, was recently discovered in non-small cell lung cancer (NSCLC). ${ }^{17}$ As it has been known earlier that CDK5/p35 activation by neuregulin subsequently activates PI3K and Akt through ErbB3 and ErbB2 receptors in cultured cortical neurons, ${ }^{18}$ the activation of CDK5, along with the other genes, may play a role in NSCLC tumorigenesis.

It has been reported that an individual's susceptibility to a disease such as lung cancer can vary depending on the presence of singlenucleotide polymorphisms (SNPs), an important class of genetic variation, in genes affecting cell proliferation or cell death. ${ }^{19-21}$ Moreover, SNPs in the coding regions or the regulatory regions of genes are more likely to cause functional differences than SNPs located elsewhere. ${ }^{19}$

Therefore, this study was undertaken to examine those possible relationship between three novel SNPs found in CDK5 promoter region and the risk of lung cancer occurrence in Korean lung cancer patients.

\section{MATERIALS AND METHODS}

Study patients

From August 2001 to February 2007, blood samples were collected from successive series of 809 participants, including 407 lung cancer cases

\footnotetext{
${ }^{1}$ Genomic Research Center for Lung and Breast/Ovarian Cancers, Korea University Anam Hospital, Seoul, Korea; ${ }^{2}$ Department of Molecular and Cell Biology, University of California, Berkeley, CA, USA; ${ }^{3}$ Division of Oncology/Hematology, Department of Internal Medicine, Korea University Anam Hospital, Seoul, Korea; ${ }^{4}$ Department of Internal Medicine and Division of Brain Korea 21 Project for Biomedical Science, Seoul, Korea; ${ }^{5}$ DNA Link Inc., Seoul, Korea and ${ }^{6}$ Department of Internal Medicine, Inha University College of Medicine, Incheon, Korea

Correspondence: Dr YH Kim, Division of Oncology/Hematology, Department of Internal Medicine, Korea University Anam Hospital, 126-1, Anam-dong 5 ka, Seongbuk-ku, Seoul 137-705, Korea.

E-mail: yhk0215@korea.ac.kr

Received 17 October 2008; revised 8 January 2009; accepted 23 February 2009; published online 3 April 2009
} 
a
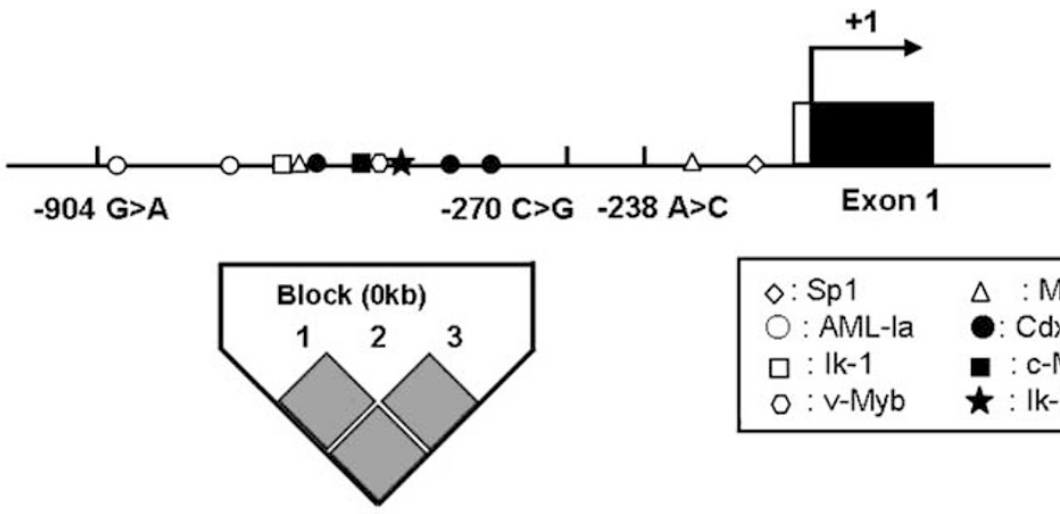

\begin{tabular}{|ll|}
\hline$\diamond:$ Sp1 & $\triangle:$ MZF1 \\
$0:$ AML-la & $:$ CdxA \\
$\square:$ Ik-1 & $\mathbf{a}:$ c-Myb \\
$0:$ v-Myb & $\star$ : lk-2 \\
\hline
\end{tabular}

b

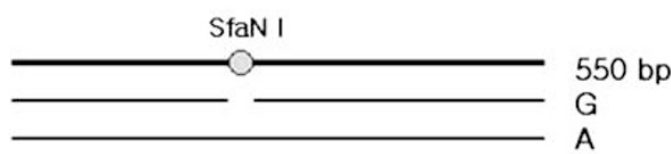

M GG GA AA

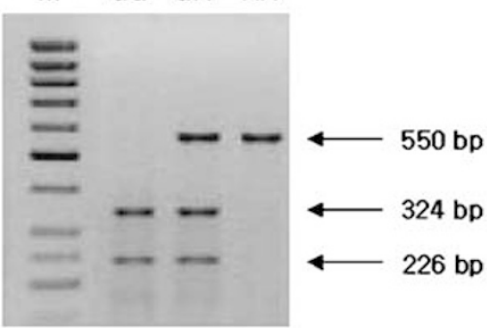

c
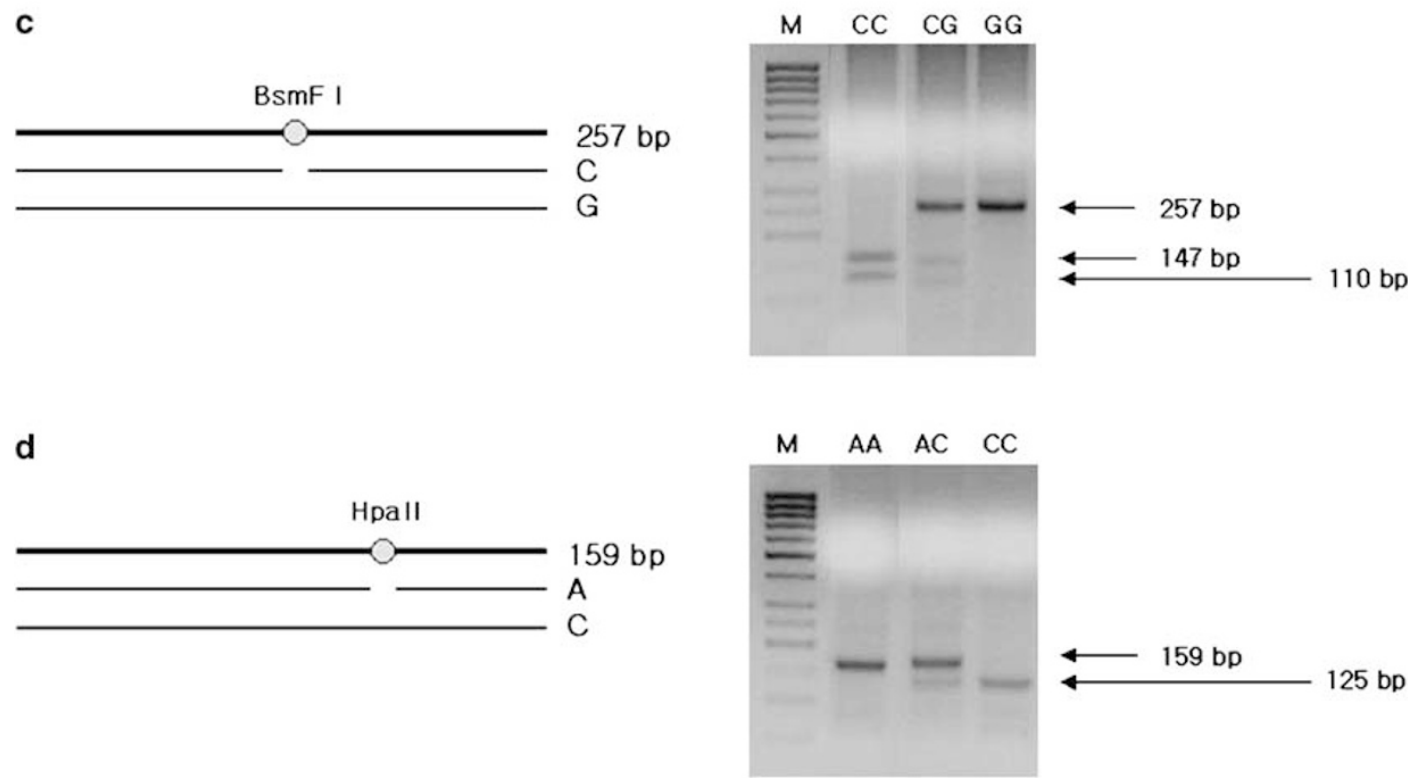

d

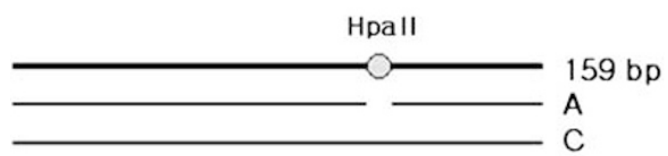

Figure 1 The cyclin-dependent kinase 5 (CDK5) gene promoter region and genotyping. In this schematic, the translation initiation site for the CDK5 protein is indicated as +1 (a). Polymorphism analysis of -904 (b), -270 (c) and -238 (d) loci in the CDK5 gene by PCR, followed by specific restriction enzyme digestion. The left panel of each figure represents schematic presentation of the enzyme restriction pattern generated by polymorphisms at each locus. As indicated on the top of each lane on the right panels, representative samples with polymorphisms at $-904,-270$ and -238 are shown. Lane $M$ was loaded with appropriate DNA markers.

and 402 controls. The lung cancer cases were recruited from patients at the Korea Genomic Research Center for Lung and Breast/Ovarian Cancer and Inha University Medical Center, and age- and gender- matched control individuals were selected from a pool of healthy volunteers at the Cardiovascular Genome Center, Genomic Research Center for Allergy and Respiratory Diseases and Keimyung University Dongsan Medical Center. All participants were given a structured questionnaire that elicited information on diet, smoking status, alcohol consumption, lifestyle and medical history. All study participants were ethnic Koreans, and their written consent and institutional review board approval for the study protocol were obtained.

\section{Screening and genotyping of CDK5 promoter polymorphism}

The genotype analysis was carried out by investigators blinded to all patient identifiers and information. Genomic DNA of all participants was isolated from blood samples using a Puregene blood DNA kit (Gentra, Minneapolis, MN, USA), according to the manufacturer's instructions. To identify SNPs in the 
Table 1 Baseline characteristics of study participants

\begin{tabular}{lccc}
\hline & $\begin{array}{c}\text { Cases } \\
(\mathrm{n}=407)\end{array}$ & $\begin{array}{c}\text { Controls } \\
(\mathrm{n}=402)\end{array}$ & P-value \\
\hline Age (years) & $60.78 \pm 0.47$ & $60.76 \pm 0.54$ & $0.808^{\mathrm{a}}$ \\
Gender & & & \\
Male & 303 & 297 & \\
Female & 104 & 105 & $0.854^{\mathrm{b}}$ \\
& & & \\
Smoking status & & & \\
$\quad$ Non-smoker & 107 & 162 & \\
Smoker & 289 & 147 & $<0.001^{\mathrm{b}}$ \\
Drinking status & & & \\
Non-drinker & & & \\
Drinker & 118 & 72 & \\
& 195 & 139 & \\
Stage & & & \\
1-3a & & - & \\
3b-4 & 84 & - & \\
Cell type & 227 & & \\
Adenocarcinoma (AdC) & & & \\
Squamus cell carcinoma (SqC) & 121 & & \\
Other carcinomas & 107 & & \\
\hline
\end{tabular}

aMann-Whitney test.

b $\chi^{2}$-test.

promoter of the CDK5 gene, the genomic DNA of 24 randomly selected samples from the lung cancer patients was amplified for the $5^{\prime}$ regulatory region $(\sim 3 \mathrm{~kb})$ from the translation initiation site of the CDK5 gene. PCR amplification was carried out in a PTC-225 Peltier Thermal cycler (M) research Inc., Waltham, MA, USA) using AmpliTaqGold (Roche, Branchburg, NJ, USA). An Applied Biosystems 3700 DNA analyzer (Applied Biosystems, Foster City, CA, USA) was used for direct sequencing. Next, we focused on the three SNPs ( $-904,-270$ and -238 locus) of the CDK5 gene using the PCR-based restriction fragment length polymorphism (PCR-RFLP) method for further analyses of the three CDK5 SNPs in 407 lung cancer cases and 402 controls. The designs of primers for RFLP were based on the GenBank sequence (NT_007914). The genotypes of the sample were amplified by PCR using $5^{\prime}$-CTAGGCAGAGCCATCACTTA- $3^{\prime}$ (forward) and $5^{\prime}$-GATTTTAGTGGAG GGACACA- $3^{\prime}$ (reverse) primer pairs for -904 locus, and 5'-CTGGGAGCACAT AAAAGGAA-3' (forward) and 5'-CTTCTGGGGCTTGTAGTCCT-3' (reverse) primer pairs for -270 locus, and $5^{\prime}$-ACTTGAAGTCCAAGGTTTGC-3' (forward) and 5'-CTTCTGGGGCTTGTAGTCCT- $3^{\prime}$ (reverse) primer pairs for -238 locus. The PCR was carried out using $50 \mathrm{ng}$ of genomic DNA, $1 \times$ Taq buffer, $10 \mu \mathrm{M}$ each of primers, $200 \mu \mathrm{M} 2^{\prime}$-deoxynucleoside $3^{\prime}$-triphosphate and

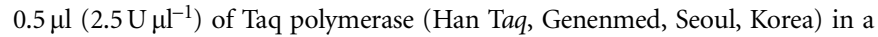
final volume of $20 \mu$ l. PCR amplification was carried out for 35 or 40 cycles with heat denaturing at a temperature of $94^{\circ} \mathrm{C}$ for $1 \mathrm{~min}$, annealing at $55^{\circ} \mathrm{C}$ (-904 locus), $60^{\circ} \mathrm{C}$ ( -270 locus), $58^{\circ} \mathrm{C}$ ( -238 locus) for $30 \mathrm{~s}$, primer extending at $72{ }^{\circ} \mathrm{C}$ for $30 \mathrm{~s}$ and a final step at $72^{\circ} \mathrm{C}$ for $7 \mathrm{~min}$. PCR products were verified by agarose gel electrophoresis. The PCR products were digested with restriction endonuclease to determine the genotype of each participant. DNA fragments were separated using 2-3\% agarose gel and were detected by ethidium bromide staining. In the -904 locus, the $\mathrm{A}$ to $\mathrm{G}$ transition created an SfaNI (New England Biolabs, Beverly, MA, USA) restriction site. The PCR product containing the $\mathrm{G}$ allele was broken into two fragments, whereas the PCR product containing the A allele could not be cut by SfaNI (Figure 1b). In the same manner, the $\mathrm{G}$ to $\mathrm{C}$ transition in the -270 locus created a BsmFI (New England Biolabs) restriction site (Figure 1c), whereas the A to $\mathrm{C}$ transition in the -238 locus created a HpaII (New England Biolabs) restriction site (Figure 1d). More than 10\% of the DNA samples were randomly selected for genotype confirmation using the SNaPshot (PE Applied Biosystems, Warrington, UK) ddNTP primer extension method as described earlier, ${ }^{22}$ and the results were in complete concordance.

\section{Statistical analysis}

Allele frequencies, genotype frequencies and departures of the genotype distribution from Hardy-Weinberg equilibrium for each SNP were analyzed using the $\chi^{2}$-test or Fisher's exact test. Linkage disequilibrium (LD) was tested on pairwise combinations of SNPs using the absolute value of the standardized measure of $\mathrm{LD},\left|D^{\prime}\right|$, calculated using the Haploview program version 3.2. A $P$-value of $<0.05$ was considered statistically significant. Genotype-specific risks were estimated as odd ratios (ORs) with associated $95 \%$ confidence intervals (CIs) by unconditional logistic regression and adjusted for age, gender and smoking status. In the codominant model, the common homozygous genotype in the controls was defined as the reference group; the rare homozygous and heterozygous genotypes were variant genotypes, and their effects were individually estimated by comparison with the reference. Alternatively, the rare homozygotes and the heterozygotes were combined to form the reference group and compared with the common homozygote in the dominant model. In the recessive model, only the rare homozygotes were defined as the variant genotype, whereas the other two genotypes were combined as the reference. Statistical analyses were carried out using the SAS system, version 9.1 (SAS Institute, Cary, NC, USA).

\section{RESULTS}

The study population consisted of 407 lung cancer patients and 402 controls (Table 1). All the clinical characteristics, except for smoking history, were not significantly different between the cases and controls. The initial screening of $C D K 5$ promoter region from the genomic DNA of 24 Korean lung cancer patients identified three polymorphisms: $-904 \mathrm{G}>\mathrm{A},-270 \mathrm{C}>\mathrm{G}$ and $-238 \mathrm{~A}>\mathrm{C}$, and the minor allele frequencies of the study population were $0.260,0.313$ and 0.298 , respectively. Further genotyping on the lung cancer and control populations showed that the genotype distributions of the three polymorphisms among all study populations were in Hardy-Weinberg equilibrium. Furthermore, the three polymorphisms showed strong LD in both the controls and the cases $\left(\left|D^{\prime}\right| \geqslant 0.92, P<0.0001\right)$ (data not shown).

The distribution of the selected CDK5 genotypes and the estimated associations between the CDK5 functional SNPs and lung cancer risk are shown in Table 2. Among the distributions of the genotypes between the overall lung cancer cases and the controls, the -904 G>A genotype was shown to affect lung cancer risk. Patients with the A allele at the site had a significantly higher risk of lung cancer than those with only the $\mathrm{G}$ allele (dominant model; adjusted $\mathrm{OR}=1.53$, 95\% CI=1.02-2.32). Genotypes $-270 \mathrm{C}>\mathrm{G}$ and $-238 \mathrm{~A}>\mathrm{C}$ were also shown to be somewhat related to the increase in risk of lung cancer; however, their CIs were too wide to be statistically significant (dominant model; $-270 \mathrm{C}>\mathrm{G} \mathrm{OR}=1.18,95 \% \mathrm{CI}=0.86-1.61 ;-237$ $\mathrm{A}>\mathrm{C}$ OR $=1.20,95 \% \mathrm{CI}=0.88-1.65)$. In the analysis stratified by gender, smoking and drinking history, the effect of A genotype of $-904 \mathrm{G}>\mathrm{A}$ on the lung cancer risk was found in females $(\mathrm{OR}=2.02,95 \% \mathrm{CI}=1.12-3.64)$ and non-smokers $(\mathrm{OR}=1.78,95 \%$ $\mathrm{CI}=1.06-3.00)$ in the dominant model.

Subsequent haplotype analysis of the three CDK5 SNP sites (-904 $\mathrm{G}>\mathrm{A},-270 \mathrm{C}>\mathrm{G},-238 \mathrm{~A}>\mathrm{C}$ ) showed that the A-G-C haplotype was associated with a higher overall risk of lung cancer $(\mathrm{OR}=1.59$, $95 \% \mathrm{CI}=1.16-2.18$ ) in the dominant model (Table 3). Further analysis stratified by gender, smoking and drinking history showed that the individuals carrying the $\mathrm{A}-\mathrm{G}-\mathrm{C}$ haplotype had significantly higher risks of lung cancer in subgroups, including females, non-smokers and 
Table 2 Distribution of SNPs and their association with lung cancer risk in overall population and subpopulation stratified by gender, smoking and drinking status

\begin{tabular}{|c|c|c|c|c|c|c|c|}
\hline Group & Loci & Genotype & Cases (\%) & Controls (\%) & Dominant $O R(95 \% \mathrm{Cl})^{\mathrm{a}}$ & Recessive OR $(95 \% \mathrm{Cl})^{\mathrm{a}}$ & Codominant OR $(95 \% \mathrm{Cl})^{\mathrm{a}}$ \\
\hline \multirow[t]{9}{*}{ Overall } & $-904 \mathrm{G}>\mathrm{A}$ & GG & $183(45.1)$ & $225(57.8)$ & & & \\
\hline & & GA & $179(44.1)$ & $126(32.4)$ & $1.52(1.11-2.09)^{\mathrm{b}}$ & $1.19(0.71-2.00)$ & $1.32(1.04-1.67)^{\mathrm{b}}$ \\
\hline & & AA & $44(10.8)$ & $38(9.8)$ & & & \\
\hline & $-270 C>G$ & $\mathrm{CC}$ & $183(45.2)$ & $198(50.6)$ & & & \\
\hline & & $C G$ & $178(44.0)$ & $141(36.1)$ & $1.18(0.86-1.61)$ & $0.83(0.51-1.34)$ & $1.04(0.83-1.31)$ \\
\hline & & GG & $44(10.8)$ & $52(13.3)$ & & & \\
\hline & $-238 A>C$ & $\mathrm{AA}$ & $182(45.1)$ & $200(52.5)$ & & & \\
\hline & & $A C$ & $178(44.1)$ & $135(35.4)$ & $1.20(0.88-1.65)$ & $0.87(0.53-1.41)$ & $1.07(0.85-1.35)$ \\
\hline & & $\mathrm{CC}$ & $44(10.8)$ & $46(12.1)$ & & & \\
\hline \multirow[t]{9}{*}{ Male } & $-904 \mathrm{G}>\mathrm{A}$ & GG & $139(46.0)$ & $168(59.2)$ & & & \\
\hline & & GA & $129(42.2)$ & 85 (29.9) & $1.33(0.91-1.97)$ & $1.05(0.57-1.94)$ & $1.18(0.89-1.58)$ \\
\hline & & $\mathrm{AA}$ & $34(11.3)$ & 31 (10.9) & & & \\
\hline & $-270 C>G$ & $\mathrm{CC}$ & $140(46.5)$ & $148(51.8)$ & & & \\
\hline & & $C G$ & $127(42.2)$ & $96(33.6)$ & $1.03(0.70-1.52)$ & $0.72(0.41-1.27)$ & $0.94(0.71-1.24)$ \\
\hline & & GG & $34(11.3)$ & $42(14.7)$ & & & \\
\hline & $-238 A>C$ & AA & $140(46.5)$ & $150(54.4)$ & & & \\
\hline & & $A C$ & $127(42.2)$ & $90(32.6)$ & $1.06(0.72-1.56)$ & $0.76(0.43-1.36)$ & $0.97(0.73-1.28)$ \\
\hline & & $\mathrm{CC}$ & 34 (11.3) & $36(13.0)$ & & & \\
\hline \multirow[t]{9}{*}{ Female } & $-904 \mathrm{G}>\mathrm{A}$ & GG & $44(42.3)$ & $57(54.3)$ & & & \\
\hline & & GA & $50(48.1)$ & $41(39.1)$ & $2.02(1.12-3.64)^{\mathrm{b}}$ & $1.55(0.55-4.38)$ & $1.67(1.05-2.66)^{\mathrm{b}}$ \\
\hline & & $A A$ & $10(9.6)$ & $7(6.7)$ & & & \\
\hline & $-270 C>G$ & $\mathrm{CC}$ & $43(41.4)$ & $50(47.6)$ & & & \\
\hline & & $C G$ & $51(49.0)$ & 45 (42.9) & $1.58(0.88-2.86)$ & $1.09(0.42-2.82)$ & $1.33(0.85-2.07)$ \\
\hline & & GG & $10(9.6)$ & $10(9.5)$ & & & \\
\hline & $-238 A>C$ & $A A$ & $42(40.8)$ & $50(47.6)$ & & & \\
\hline & & $A C$ & $51(49.5)$ & $45(42.9)$ & $1.60(0.88-2.88)$ & $1.09(0.42-2.83)$ & $1.33(0.85-2.08)$ \\
\hline & & $\mathrm{CC}$ & $10(9.7)$ & $10(9.5)$ & & & \\
\hline \multirow[t]{9}{*}{ Non-smoker } & $-904 \mathrm{G}>\mathrm{A}$ & GG & $43(40.2)$ & $86(53.1)$ & & & \\
\hline & & $\mathrm{GA}$ & $54(50.5)$ & $63(38.9)$ & $1.78(1.06-3.00)^{\mathrm{b}}$ & $1.13(0.45-2.80)$ & $1.45(0.97-2.17)$ \\
\hline & & $A A$ & $10(9.4)$ & $13(8.0)$ & & & \\
\hline & $-270 C>G$ & $\mathrm{CC}$ & $42(39.3)$ & $75(46.6)$ & & & \\
\hline & & $\mathrm{CG}$ & $55(51.4)$ & 69 (42.9) & $1.41(0.84-2.38)$ & $0.84(0.35-1.99)$ & $1.18(0.79-1.75)$ \\
\hline & & $\mathrm{GG}$ & $10(9.4)$ & $17(10.6)$ & & & \\
\hline & $-238 A>C$ & $\mathrm{AA}$ & $41(38.7)$ & $76(47.2)$ & & & \\
\hline & & $A C$ & 55 (51.9) & 69 (42.9) & $1.45(0.86-2.44)$ & $0.87(0.37-2.08)$ & $1.21(0.81-1.79)$ \\
\hline & & $\mathrm{CC}$ & $10(9.4)$ & $16(9.9)$ & & & \\
\hline \multirow[t]{9}{*}{ Smoker } & $-904 \mathrm{G}>\mathrm{A}$ & GG & $134(46.5)$ & $82(56.2)$ & & & \\
\hline & & GA & $120(41.7)$ & 49 (33.6) & $1.35(0.90-2.05)$ & $1.25(0.65-2.44)$ & $1.24(0.91-1.68)$ \\
\hline & & $\mathrm{AA}$ & $34(11.8)$ & $15(10.3)$ & & & \\
\hline & $-270 C>G$ & $\mathrm{CC}$ & $136(47.4)$ & $74(50.3)$ & & & \\
\hline & & $C G$ & $117(40.8)$ & $52(35.4)$ & $0.99(0.66-1.50)$ & $0.82(0.45-1.50)$ & $0.95(0.71-1.28)$ \\
\hline & & GG & 34 (11.9) & $21(14.3)$ & & & \\
\hline & $-238 A>C$ & $A A$ & $136(47.4)$ & $74(50.1)$ & & & \\
\hline & & $A C$ & $117(40.1)$ & $52(35.6)$ & $1.01(0.67-1.52)$ & $0.86(0.47-1.59)$ & $0.97(0.72-1.30)$ \\
\hline & & $\mathrm{CC}$ & 34 (11.9) & $20(13.7)$ & & & \\
\hline \multirow[t]{9}{*}{ Non-drinker } & $-904 \mathrm{G}>\mathrm{A}$ & GG & $46(39.3)$ & $37(51.4)$ & & & \\
\hline & & $\mathrm{GA}$ & $58(49.6)$ & $29(40.3)$ & $1.88(1.01-3.50)^{\mathrm{b}}$ & $1.70(0.59-4.85)$ & $1.63(1.00-2.64)^{\mathrm{b}}$ \\
\hline & & AA & $13(11.1)$ & $6(8.3)$ & & & \\
\hline & $-270 C>G$ & $\mathrm{CC}$ & $49(42.4)$ & $33(45.8)$ & & & \\
\hline & & CG & $55(47.4)$ & $30(41.7)$ & $1.21(0.65-2.25)$ & $0.99(0.38-2.57)$ & $1.11(0.70-1.76)$ \\
\hline & & GG & $12(10.3)$ & $9(12.5)$ & & & \\
\hline & $-238 A>C$ & AA & $48(41.7)$ & $33(45.8)$ & & & \\
\hline & & $A C$ & $55(47.8)$ & $30(41.7)$ & $1.22(0.66-2.27)$ & $0.99(0.38-2.57)$ & $1.11(0.70-1.77)$ \\
\hline & & $\mathrm{CC}$ & $12(10.4)$ & $9(12.5)$ & & & \\
\hline \multirow[t]{9}{*}{ Drinker } & $-904 \mathrm{G}>\mathrm{A}$ & GG & $90(46.2)$ & $82(59.4)$ & & & \\
\hline & & $\mathrm{GA}$ & $80(41.0)$ & $43(31.2)$ & $1.64(1.03-2.62)^{\mathrm{b}}$ & $1.71(0.80-3.64)$ & $1.46(1.03-2.06)^{b}$ \\
\hline & & $A A$ & $25(12.8)$ & $13(9.4)$ & & & \\
\hline & $-270 C>G$ & $\mathrm{CC}$ & $90(46.2)$ & $70(50.4)$ & & & \\
\hline & & $C G$ & $80(41.0)$ & $49(35.3)$ & $1.05(0.66-1.68)$ & $0.92(0.47-1.80)$ & $1.00(0.72-1.40)$ \\
\hline & & GG & $25(12.8)$ & $20(14.4)$ & & & \\
\hline & $-238 A>C$ & $A A$ & $90(46.2)$ & $70(50.7)$ & & & \\
\hline & & $A C$ & $80(41.0)$ & $49(35.5)$ & $1.07(0.67-1.70)$ & $0.97(0.49-1.91)$ & $1.03(0.74-1.43)$ \\
\hline & & $\mathrm{CC}$ & $25(12.8)$ & $19(13.8)$ & & & \\
\hline
\end{tabular}

Abbreviations: $\mathrm{Cl}$, confidence interval; ORs, odds ratios; SNPs, single-nucleotide polymorphisms. 
Table 3 Distribution of haplotypes of selected SNPs of CDK5 and their association with lung cancer risk in overall population and subpopulation stratified by gender, smoking and drinking status

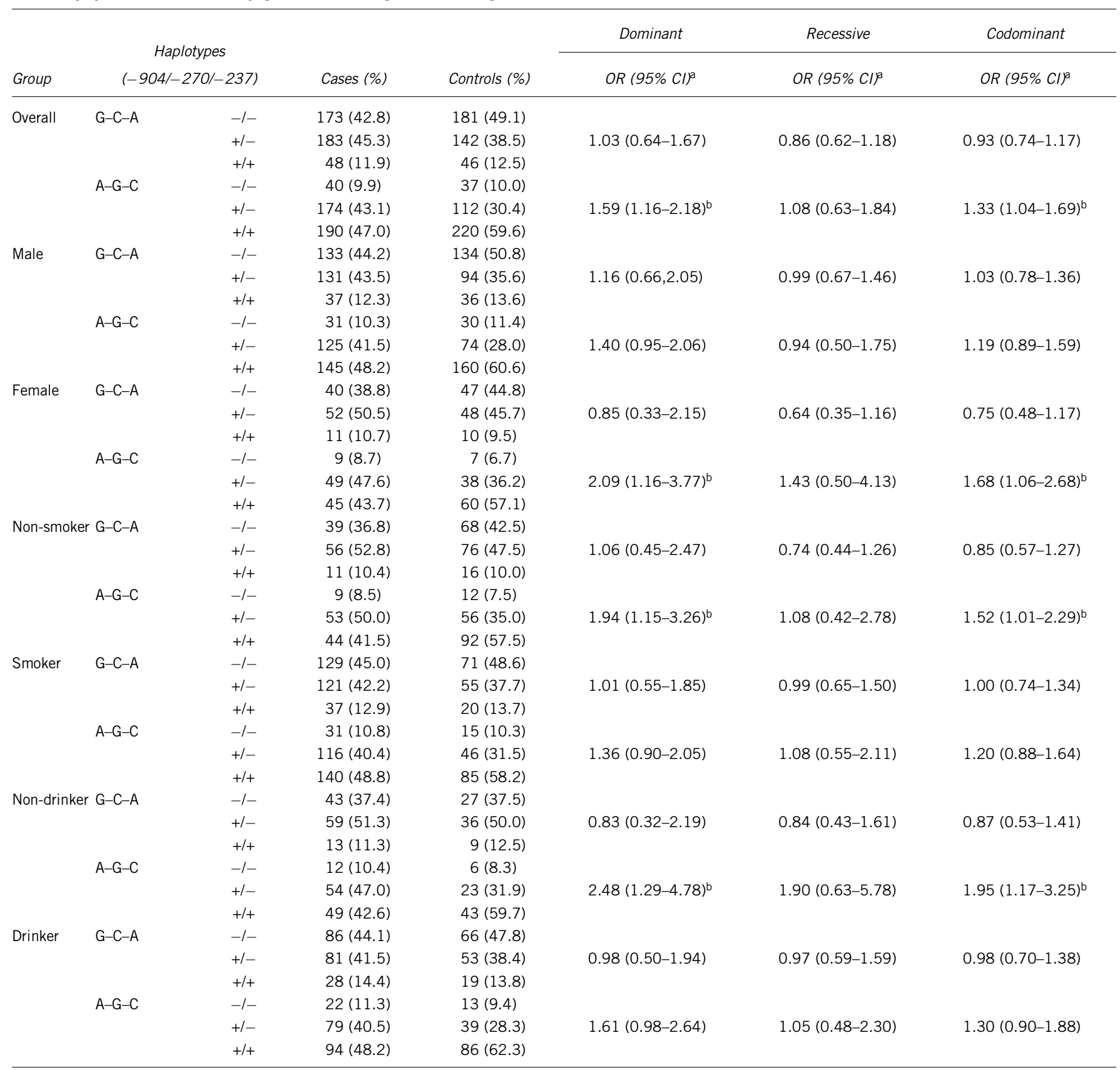

Abbreviations: CDK5, cyclin-dependent kinase 5; Cl, confidence interval; ORs, odds ratios; SNPs, single-nucleotide polymorphisms. aORs and $95 \% \mathrm{Cl}$ were calculated by logistic regression model and adjusted for age, gender and smoking status.

$\mathrm{a}$ ORs and
$\mathrm{b} P<0.03$.

non-drinkers (female: $\mathrm{OR}=2.09,95 \%$ CI 1.16-3.77; non-smoker: $\mathrm{OR}=1.94 ， 95 \% \quad \mathrm{CI}=1.15-3.26 ; \quad$ non-drinker: $\mathrm{OR}=2.48, \quad 95 \%$ $\mathrm{CI}=1.29-4.78)$.

\section{DISCUSSION}

It is quite possible that DNA sequence variations in the CDK5, a gene that has recently been studied for its association with non-neuronal cell differentiation and apoptosis in many areas, may lead to alteration in the activity of CDK5, which can cause individual differences in lung cancer susceptibility. Indeed, a recent study on CDK5-mediated regulation of the PIKE-A-Akt pathway suggests an important clue to the association of CDK5 with tumorigenesis, as the accumulation of phosphorylated PIKE-A (PI3-kinase enhancer), a recently identified GTP-binding protein shown to regulate the PI3K-Akt pathway and activation of Akt in the nucleus of glioblastoma cell, is a CDK5dependent activity, ${ }^{23}$ suggesting possible association of CDK5 with non-neuronal cell survival. This was further supported by another study that showed the overexpression of CDK5, along with the other downstream components of the EGFR-family signaling pathway, such as AKT1 and SHC1, as a direct result of gene amplification, specifically in lung cancer cells, ${ }^{17}$ signifying that the alteration of the CDK5 gene may play a causal role in the development of lung cancer. 
In this study, we evaluated the associations between three newly found SNPs $(-904 \mathrm{G}>\mathrm{A},-270 \mathrm{C}>\mathrm{G}$ and $-238 \mathrm{~A}>\mathrm{C})$ in the promoter region of the CDK5 gene and the risk for lung cancer. Of the three SNPs, $-904 \mathrm{G}>$ A showed a possibility to play an important role in carcinogenesis (overall $\mathrm{OR}=1.53,95 \% \mathrm{CI}=1.11-2.09$ ), whereas the other two SNPs $(-270 \mathrm{C}>\mathrm{G}$ and $-238 \mathrm{~A}>\mathrm{C})$ showed some increase in the risk of lung cancer, although not adequately proven to be statistically significant.

Many studies showed that analysis of haplotypes has a greater power to detect the association with disease than an individual polymorphism. Moreover, haplotype analysis offers the advantages of not assuming that any of the genotyped polymorphisms is functional, and it allows for the possibility of an ungenotyped functional variant to be in LD with the genotyped polymorphisms. ${ }^{24-27}$ Therefore, we conducted a subsequent analysis on $C D K 5$ haplotypes consisting of $-904 \mathrm{G}>\mathrm{A},-270 \mathrm{C}>\mathrm{G}$ and $-238 \mathrm{~A}>\mathrm{C}$ polymorphisms, which are in strong $\mathrm{LD}$. In the dominant haplotype analysis, the A-G-C haplotype of the three polymorphic sites was shown to be related to the higher risk of lung cancer (overall $\mathrm{OR}=1.59,95 \% \mathrm{CI}=1.16-2.18$ ). Notably, our stratified analyses of CDK5 showed that, when having the $\mathrm{A}-\mathrm{G}-\mathrm{C}$ haplotype, the risk of lung cancer increased significantly in females, non-smokers and non-drinkers (female: $\mathrm{OR}=2.09,95 \% \mathrm{CI}=1.16-3.77$; non-smoker: $\mathrm{OR}=1.94,95 \%$ $\mathrm{CI}=1.15-3.26$; non-drinker: $\mathrm{OR}=2.48,95 \% \mathrm{CI}=1.29-4.78)$. To examine whether the A-G-C haplotype influences promoter activity of the CKD5 gene, the CDK5 promoter sequence connected to the luciferase reporter gene was transfected into NSCLC cell lines. However, we found no significant correlation (data not shown).

Tobacco smoking has well been established to play a critical role in the development of lung cancer; however, only a fraction of the smokers actually develops cancer. Moreover, the cause of increasing incidence of lung cancer in never-smokers has never been clearly explained.

This observation suggests that individual genetic variations may determine susceptibility to lung cancer. The present result on our study that shows a close association between lung cancer in Korean population and the polymorphisms in the promoter region of CDK5 further validates this claim. The GWA database on various ethnicities has been reported to have no frequency data on $-270 \mathrm{C}>\mathrm{G}$ polymorphism, whereas data on the $-904 \mathrm{G}>\mathrm{A}$ and $-238 \mathrm{~A}>\mathrm{C}$ polymorphisms have been reported (HmapEU, 0.25 and 0.21 ; HmapCN, 0.26 and 0.26; HmapJP, 0.33 and 0.30; HmapNG, 0.43 and 0.20, respectively).

To the best of our knowledge, this is the first study to delineate the association between $C D K 5$ promoter polymorphisms and the risk of lung cancer, and to show that one of the CDK5 polymorphisms, -904 $\mathrm{G}>\mathrm{A}$, and the A-G-C haplotype ( $-904 \mathrm{~A} /-270 \mathrm{G} /-238 \mathrm{C}$ ) cause overall increase in the susceptibility of lung cancer. Moreover, subsequent stratified analyses showed statistically significant increases in the risk of lung cancer in females, non-smokers and non-drinkers who have the A-G-C haplotype of the three polymorphic sites. Therefore, the present result suggests an important association between the genetic polymorphisms of CDK5 and lung cancer development, and the necessity for further functional studies on the relationship between the $C D K 5$ gene and lung cancer.

\section{ACKNOWLEDGEMENTS}

We thank Young Lim, Dong-Hoon Shin, Choon-Sik Park and Yangsoo Jang for sample collection and provision. This study was supported by a grant of the Korea Health 21 R\&D Project, Ministry of Health \& Welfare, Republic of Korea (A010250).
1 Lew, J., Beaudette, K., Litwin, C. M. \& Wang, J. H. Purification and characterization of a novel proline-directed protein kinase from bovine brain. J. Biol. Chem. 267, 13383-13390 (1992a)

2 Lew, J., Winkfein, R. J., Paudel, H. K. \& Wang, J. H. Brain proline-directed protein kinase is a neurofilament kinase which displays high sequence homology to p34cdc2. J. Biol. Chem. 267, 25922-25926 (1992b).

3 Chen, F. \& Studzinski, G. P. Expression of the neuronal cyclin-dependent kinase 5 activator p35Nck5a in human monocytic cells is associated with differentiation. Blood 97, 3763-3767 (2001).

4 Tsai, L. H., Takahashi, T., Caviness, V. S. Jr. \& Harlow, E. Activity and expression pattern of cyclin-dependent kinase 5 in the embryonic mouse nervous system. Development 119, 1029-1040 (1993).

5 Chen, F. \& Studzinski, G. P. Cyclin-dependent kinase 5 activity enhances monocytic phenotype and cell cycle traverse in 1,25-dihydroxyvitamin D3-treated HL60 cells. Exp. Cell Res. 249, 422-428 (1999).

6 Chen, F., Wang, Q., Wang, X. \& Studzinski, G. P. Up-regulation of Egr1 by 1,25-dihydroxyvitamin D3 contributes to increased expression of p35 activator of cyclin-dependent kinase 5 and consequent onset of the terminal phase of HL6O cell differentiation. Cancer Res. 64, 5425-5433 (2004).

7 Gao, C. Y., Rampalli, A. M., Cai, H. C., He, H. Y. \& Zelenka, P. S. Changes in cyclin dependent kinase expression and activity accompanying lens fiber cell differentiation. Exp. Eye Res. 69, 695-703 (1999).

8 Lazaro, J. B., Kitzmann, M., Poul, M. A., Vandromme, M., Lamb, N. J. \& Fernandez, A. Cyclin dependent kinase 5 , cdk5, is a positive regulator of myogenesis in mouse $\mathrm{C} 2$ cells. J. Cell Sci. 110 (Pt 10), 1251-1260 (1997).

9 Lilja, L., Yang, S. N., Webb, D. L., Juntti-Berggren, L., Berggren, P. O. \& Bark, C. Cyclindependent kinase 5 promotes insulin exocytosis. J. Biol. Chem. 276, 34199-34205 (2001).

10 Session, D. R., Fautsch, M. P., Avula, R., Jones, W. R., Nehra, A. \& Wieben, E. D. Cyclin-dependent kinase 5 is expressed in both Sertoli cells and metaphase spermatocytes. Fertil. Steril. 75, 669-673 (2001).

11 Studzinski, G. P. \& Harrison, J. S. The neuronal cyclin-dependent kinase 5 activator p35Nck5a and Cdk5 activity in monocytic cells. Leuk. Lymphoma 44, 235-240 (2003).

12 Strock, C. J., Park, J. I., Nakakura, E. K., Bova, G. S., Isaacs, J. T., Ball, D. W. et al. Cyclin-dependent kinase 5 activity controls cell motility and metastatic potential of prostate cancer cells. Cancer Res. 66, 7509-7515 (2006).

13 Liu, R., Tian, B., Gearing, M., Hunter, S., Ye, K. \& Mao, Z. Cdk5-mediated regulation of the PIKE-A-Akt pathway and glioblastoma cell invasion. Proc. Natl Acad. Sci. USA 105, 7570-7575 (2008).

14 Lin, H., Chen, M. C., Chiu, C. Y., Song, Y. M. \& Lin, S. Y. Cdk5 regulates STAT3 activation and cell proliferation in medullary thyroid carcinoma cells. J. Biol. Chem. 282, 2776-2784 (2007).

15 Sandal, T., Stapnes, C., Kleivdal, H., Hedin, L. \& Doskeland, S. O. A novel, extraneuronal role for cyclin-dependent protein kinase 5 (CDK5): modulation of cAMPinduced apoptosis in rat leukemia cells. J. Biol. Chem. 277, 20783-20793 (2002).

$16 \mathrm{Fu}$, A. K., Fu, W. Y., Ng, A. K., Chien, W. W., Ng, Y. P., Wang, J. H. et al. Cyclindependent kinase 5 phosphorylates signal transducer and activator of transcription 3 and regulates its transcriptional activity. Proc. Natl Acad. Sci. USA 101, 6728-6733 (2004).

17 Lockwood, W. W., Chari, R., Coe, B. P., Girard, L., Macaulay, C., Lam, S. et al. DNA amplification is a ubiquitous mechanism of oncogene activation in lung and other cancers. Oncogene 27, 4615-4624 (2008).

18 Bogush, A., Pedrini, S., Pelta-Heller, J., Chan, T., Yang, Q., Mao, Z. et al. AKT and CDK5/p35 mediate brain-derived neurotrophic factor induction of DARPP-32 in medium size spiny neurons in vitro. J. Biol. Chem. 282, 7352-7359 (2007).

19 Cargill, M., Altshuler, D., Ireland, J., Sklar, P., Ardlie, K., Patil, N. et al. Characterization of single-nucleotide polymorphisms in coding regions of human genes. Nat. Genet. 22, 231-238 (1999).

20 Ramensky, V., Bork, P. \& Sunyaev, S. Human non-synonymous SNPs: server and survey. Nucleic Acids Res. 30, 3894-3900 (2002).

21 Wang, D. G., Fan, J. B., Siao, C. J., Berno, A., Young, P., Sapolsky, R. et al. Large-scale identification, mapping, and genotyping of single-nucleotide polymorphisms in the human genome. Science 280, 1077-1082 (1998).

22 Sung, J. S., Han, S. G., Whang, Y. M., Shin, E. S., Lee, J. W., Lee, H. J. et al. Putative association of the single nucleotide polymorphisms in RASSF1A promoter with Korean lung cancer. Lung Cancer 61, 301-308 (2008).

23 Liu, R., Tian, B., Gearing, M., Hunter, S., Ye, K. \& Mao, Z. Cdk5-mediated regulation of the PIKE-A-Akt pathway and glioblastoma cell invasion. Proc. Natl Acad. Sci. USA 105, 7570-7575 (2008).

24 Bader, J. S. The relative power of SNPs and haplotype as genetic markers for association tests. Pharmacogenomics 2, 11-24 (2001).

25 Choi, J. E., Park, S. H., Kim, K. M., Lee, W. K., Kam, S., Cha, S. I. et al. Polymorphisms in the epidermal growth factor receptor gene and the risk of primary lung cancer: a case-control study. BMC Cancer 7, 199 (2007).

26 Judson, R. \& Stephens, J. C. Notes from the SNP vs haplotype front. Pharmacogenomics 2, 7-10 (2001).

27 Judson, R., Stephens, J. C. \& Windemuth, A. The predictive power of haplotypes in clinical response. Pharmacogenomics 1, 15-26 (2000). 